\title{
Making people buy and eat differently: lessons from the modernisation of small independent grocery stores in the early twentieth century
}

\author{
Franck $\operatorname{Cochoy}^{1}$ (D)
}

Received: 10 February 2016 / Accepted: 12 April 2017 /Published online: 29 June 2017

(C) The Author(s) 2018, corrected publication September 2018

\begin{abstract}
Food studies teach us much about foods and eaters, but despite their impressive coverage and richness, they pay little attention to what occurs between the two: they tend to neglect the many market professionals and "market-things" that act as a bridge between food products and consumers. This paper proposes to fill the gap by examining how the transformation of the grocery business and related techniques contributed to reshaping the food industry's strategies, the content of foods and the identity of eaters. This investigation was conducted by studying the trade magazine Progressive Grocer over the period 1922-1959. It shows how the journal promoted a new art of "making people buy and eat". Grocers were invited to modify their practices, hence the eaters' experience, by implementing two different strategies: a movement of "betterment" of their previous service know-how and then a more radical movement of "replacement" of this know-how by the new "self-service" arrangement. By following these two movements, we understand how grocery professionals and techniques made us buy and eat, but made us do so differently, to the extent that the grocery business and related devices changed foods as well as consumers' identities.
\end{abstract}

Keywords Market-things $\cdot$ Retailing $\cdot$ Grocery business $\cdot$ Packaging $\cdot$ Equipment $\cdot$ Modernisation

JEL Classification M31: Marketing · L66: Food · L81: Retail and wholesale trade

\footnotetext{
The original version of this article was revised: With the society's decision to opt for Open Choice the copyright of the article changed in September 2018 and the article is forthwith distributed under the terms of the Creative Commons Attribution 4.0 International License (http://creativecommons.org/licenses/by/4.0/), which permits use, duplication, adaptation, distribution and reproduction in any medium or format, as long as you give appropriate credit to the original author(s) and the source, provide a link to the Creative Commons license and indicate if changes were made.
}

Franck Cochoy

cochoy@univ-tlse2.fr

1 Université Toulouse Jean Jaurès, Toulouse, France 
Food studies tend to give priority to what occurs before or after the acquisition of foods on the marketplace. With regard to what occurs beforehand, the emphasis is placed on anthropological schemes and meanings (Levi-Strauss 2006), food habits and culture (Poulain 2002) and the sociological background of contemporary eaters (e.g. Fischler 1990). Food studies favour what occurs after the purchase of foods by paying particular attention to cooking and eating practices (Counihan 2004), focusing on human rituals and interactions around food intake (Wansink and Van Kleef 2014) and the consequences of various eating behaviours such as the transformation of food cultures (Parasecoli and Scholliers 2012), the possible globalisation of eating patterns (Wilk 2006) or the development of food-related problems and pathologies such obesity (Poulain 2009). However, despite their impressive scope and richness, these studies pay less attention to what occurs between the two events; they tend to neglect the many market professionals and "market-things" that act as a bridge between foods and consumers (advertisers, marketers, grocers, market devices, selling technologies and so on).

I propose to show how these actors and objects contributed to the (re)shaping of food consumption in the early twentieth century in the USA. In the modernised grocery environment, people cannot buy and then eat food without going through the clerks, shelves, displays, tins or boxes that not only promote but also modify the consumption experience. As we will see, grocers were invited to modify their practices, hence the eaters' experience, by implementing two different strategies: a movement of "betterment" of their previous service know-how and then a more radical movement of "replacement" of this know-how by the new "self-service" arrangement. By following these two movements, we understand how grocery professionals and techniques made us buy and eat, but made us do so differently, to the extent that the grocery business and related devices changed foods as well as consumers' identities. ${ }^{1}$

\section{Theoretical framework, data, method and narrative}

In this section, I will briefly introduce the theoretical framework my paper rests upon, present the data and method I rely on and define the narrative that I will develop to show how grocery people and technologies reshaped food consumption.

\section{Theoretical framework}

This paper shares the agenda and perspectives of a larger research stream now known as "market studies" (Araujo et al. 2011). Having strong intellectual roots in science and technology studies (STS), market studies promote a view urging social sciences to account not only for everyone but also for every thing that matters in market

\footnotetext{
${ }^{1}$ This study is based on two data-collecting sessions, one carried out at the University of California, Berkeley (14 July-8 August 2006), and the other at the Center for Research Libraries of Chicago (14-18 January 2013). I warmly thank Progressive Grocer for granting me permission to reproduce the images this paper refers to. The present paper borrows elements from previous publications (Cochoy 2014a, 2016). For a more detailed and developed approach, see the latter.
} 
environments. Of course, human actors, culture, meanings, sentiments, strategies, talks and representations still play a prominent role in social conduct and often take the lead. However, objects, artefacts, living beings and more generally all non-human agencies cannot be considered as mere material resources, as elements of a passive context or as the product of social conducts (McFall 2009). Instead, these entities often fully participate in the unfolding of various undertakings (Callon 1986); in other words, they too have "agency", i.e. the capacity to act, even when they are not "alive" by virtue of their physical characteristics. For instance, a hermetic tin preserves the food it contains, and a printed paper label describes and qualifies the product it presents. As a consequence, market situations may be described as various "agencements", where the "agency" of market professionals (Cochoy and Dubuisson-Quellier 2013) and market devices (Callon et al. 2007) combine their efforts and transformative force to achieve a given organisation of commerce-an agencement (Callon 2016). In some respects, one may consider that human actors, given their distinctive rational and intentional abilities, try to frame and direct this combination in a dynamic effort aimed at "agencing markets" (Cochoy et al. 2016).

However, a symmetrical account of how market professionals and market devices jointly shape market exchange helps understand that all the elements involved in such "market agencements" are not in full control. In particular, technologies often produce some specific and unexpected effects. As such, market devices (although the same is true for market professionals) cannot be considered as faithful intermediaries that merely act as neutral "connectors" between the two sides of supply and demand. Thanks to Antoine Hennion (2015) and Bruno Latour (1988), we have long known the extent to which intermediaries, given their often autonomous and unpredictable agency, often mutate into mediators, i.e. into entities that, rather than working as faithful messengers, modify not only the elements they are meant to convey (e.g. food) but also their origin and destination (e.g. the food industry and consumers). In this paper, I propose to examine how the transformation of the grocery business and related techniques made them act as strong mediators in the circulation of foods on the American market: as I will show, they contributed to reshaping the food industry's strategies, the content of foods and the identity of eaters. Market devices bring some new features that often produce effects that "overflow" from the frame fixed for their implementation. Market professionals ceaselessly attempt to reframe these overflows according to their initial preferences and goals (Callon 1998), but I aim to show that they also use them as foundations for a continuous "re-agencement" of their activity.

As we will see, in the early twentieth century, innovative retail technologies favoured the promotion of a new art of "making people buy and eat": the purpose was still to make people buy and eat, but to make them buy and eat differently. This idea of "making (someone) do (something)" is borrowed from Latour (1999). It helps move away from the false alternative between "sociologism" (i.e. the view according to which "doing" is the privilege of social actors who are supposed to be the only origin of action: "we do") and "technologism" (i.e. the opposite view, according to which we are not really doing anything, but instead passively driven by technological frames and forces: we are "done"). Neither sociologism nor technologism is satisfactory. If we do not fully control our action, we still assume a very large part of it. However, during the course of our action, material devices often lend us their own agency; they thus "make 
us do" the things we aim for, but given their contribution, we tend to do these things slightly differently from what we would have done alone.

\section{Data and method}

My study of how retailers and retail technologies made consumers buy their foods differently (and also buy different foods) is based on the systematic reading of the professional journal Progressive Grocer over the period 1922-1959. This magazine was aimed at small independent grocers to help them resist the competition of new forms of distribution such as chain stores and supermarkets by modernising their techniques and practices (Cochoy 2016).

I reviewed each issue of the magazine, page by page, from 1922 to 1959. I photographed every page with content directly or indirectly linked to the presentation of retailing techniques, in both the managerial and material senses (articles and advertisements). The resulting archive containing about 5000 magazine pages was classified and analysed along various thematic lines.

The method used combines the "archaeology of present time" (Cochoy 2009) with historical methods. Like an archaeologist, I base my analysis on the material forms taken by food-selling techniques (new furniture, packaging techniques, service methods and so on). This focus on the visual and material aspects of what can be seen in pictures helps gain insights that are often lacking in texts and testimonies. I combine this archaeological approach with traditional historical analysis of written documents in the form of magazine articles.

Even if systematic, this method is, at first glance, debatable, given its "single source" nature. Does not careful historical inquiry require the use of several types of sources and their subsequent triangulation? Yes, in most cases, but several arguments may nevertheless justify the single source approach as far as Progressive Grocer is concerned. Firstly, this journal is less a "source" than an historical "ocean"! Indeed, it is not a specific and tiny flow that irrigates retail history from upstream; it is rather a large and central reservoir - the leading trade magazine of its sector, with a readership of 50,000 grocers in the 1930 s, i.e. $20 \%$ of professionals at the time - that receives (downstream!) the input of various flows: contributions of journalists specialised in retailing policies and techniques, information about government regulation, facts about competition (in particular chain stores and supermarkets), advertisements from suppliers who promote various retailing devices, experiences of varied retailers and even information about consumers, be it through professional testimonies or surveys.

Secondly and consequently, the wide scope and heterogeneity of Progressive Grocer allows the information to be triangulated within itself. While many papers and advertisements are aimed at promoting particular techniques and equipment and should thus be taken with precaution as far as their real use and business potential is concerned, looking at one topic in a paper or advertisement that focuses on a different subject is a powerful means to get a better and more neutral view of the first.

The third argument is the advantages of continuously following a single source rather than intermittently covering multiple archives when trying to account for developments over a long period. Reading Progressive Grocer provides a more systematic view of the array and timing of innovations and a better chance of not missing small but nevertheless significant developments. That said, my approach is not strictly 
monomaniac: I have crossed my primary data with several secondary sources and supplemented it with knowledge obtained from major works on the same topic (Bowlby 2001; Deutsch 2001; Grandclément 2008; Spellman 2016; Strasser 1989; Tedlow 1990).

\section{Narrative}

My focus is on the modernisation of food businesses and food-buying and consumption practices in the early twentieth century. This focus is given by the name of the magazine itself: Progressive Grocer, as the title suggests, is about helping US independent grocers to move forward according to the argument that these professionals, if they want to survive, have no choice but to follow the general advances of the times. American society and economy had experienced an incredible array of changes since the beginning of the so-called "Progressive Era" in the late nineteenth century (Buenker and Kantowicz 1988), a movement the magazine's title clearly refers to.

However, talking of progress is one thing, explaining what it is or should be is another, and historians should be very careful in this respect. In particular, they should be wary of presenting the new solutions that emerged as "progressive" or "modern" and discarding other features and practices that disappeared as "regressive" or "old-fashioned". The delivery of customer service is the best example one can give for the need for such caution. Should service be considered as an outmoded feature of an archaic state of the grocery world, which could not avoid being replaced by new "modern" or "progressive" arrangements such as self-service and cash and carry methods? Most people looking at history from our contemporary context would answer positively, but early twentieth century grocers had excellent reasons to look at the issue in other terms: does service not benefit consumers and build customer loyalty for the grocer? Would abandoning it not mean regression rather than progress in this respect?

These questions help define progress according to the actors' perspective, rather than a rigid, normative and, moreover, anachronistic view. More importantly, they help identify two versions of modernisation proposed by the actors themselves. As we will see, the first version is that of "betterment": making progress is not necessarily about abandoning existing methods for new ones, but could be about improving the first. The second version is that of "replacement": instead of improving available techniques, one may also replace them with fully innovative ideas, methods and devices.

\section{Betterment}

The first modernisation effort, rather than attempting to abolish human service, aimed instead at its betterment. This betterment addressed the workforce and its tools by adopting modern equipment, telephone-assisted sales and motorised delivery services.

\section{Optimising grocers' work with proper equipment}

When Progressive Grocer was launched, independent grocers faced increasingly fierce competition from chain stores whose main force was not necessarily novel techniques, which were proposed to every business by various external suppliers (Cochoy 2016), 
but rather strong economic advantages in terms of scale that helped them buy in larger quantities at lower prices, selling more cheaply and making larger profits through volume (Strasser 1989; Tedlow 1990; Spellman 2016).

Fighting competition from chain stores did not (yet) mean getting rid of grocers but instead making them more efficient. This concern applied to employees literally from their heads to their feet. In 1927, the magazine published two detailed articles about foot-related problems, one entitled "Car[ing] of the Feet for Employees Who Stand Up All Day" (1927, 02, 16 sq.); the other "Feet Ache and Get Tired? Here are a Few Home Remedies" (1927, 03, 27 sq.). A year earlier, it provided means to assist grocers' heads that wonderfully anticipated the cognitive artefacts dear to contemporary specialists of equipped cognition (Norman 1988; Lave et al. 1984). George Reuter, a grocer from Rochester, NY, exhibited a "standing order-book [...] of things that must be cleaned or repaired in the store." Each time, a slip is made out specifying the nature of the task and the name of the employee in charge, so that nothing is forgotten and everything is perfectly controlled (1926, 11, 43 sq.). And we should not forget, regardless of these articles, all the advertisements promoting, page after page, work gloves claiming to take the greatest care of grocers' hands: Coshocton Glove Co. (1922, 07, 92); the Indianapolis gloves $(1925,10,104)$ and the Twin-seam Leather Palm Work Gloves (1925, $11,111)$. The gradient from the feet to the head, by embodying the opposing dimensions of the body and the intellect jointly involved in the business of selling, is a good illustration of the organisation of modernising grocers' work, from training employees to acquiring the equipment needed to assist them physically.

Optimising grocers' work therefore depended less on the division of labour than improving efficiency through the multiplying effect of a number of new tools aimed at assisting grocers in their daily activities. Improving work through the use of appropriate tools is a strategy that follows a typically Taylorian pattern since it focuses on finding the optimal combination of human and technical resources. An article stated that "Overequipment eats into the store profits. Under-equipment makes for inefficiency and waste. Somewhere there is a happy medium" (1926, 08, 23 sq.). Such reasoning clearly linked the issue of equipment to that of labour productivity, identifying "labour and time saving equipment, that is, equipment that promotes efficiency". The optimisation of payroll expenditure was even more important because the wage level had never been higher. The article then evoked the time factor, in the purest Taylorian style, citing the importance of every single second, the problem of managing peak periods and the particular need to satisfy customers who come during the busiest hours. In order to cope with these difficulties and find solutions to overcome them, it invited grocers to suggest to their local professional association the purchase of a pedometer. This system was to the grocery store what the chronometer was to Taylor's factory, since it enabled the number of steps taken by staff to be recorded every day and therefore comparisons to be made between several different stores. "You will find, that in one store, the same amount of sales requires twice as many steps as in another" $(1926,8,25)$.

We can then understand the paradox raised by another article claiming that one can earn money by spending a lot to acquire new and expensive equipment $(1926,07,11$ sq.). Of course, these investments represented a cost, but it was not possible to ignore the symmetric cost of service, including employees' time and effort. Moreover, the author argued there was equipment that "ke[pt] down the cost of selling" (italics in the text) or more precisely "Equipment that save[d] your time, your clerks' time, or that 
eliminates[d] waste in the process of selling." What were these devices? The items listed were mostly service-oriented devices: tools that accompany, multiply and relieve work, rather than replace it; they were objects that did not affect the general organisation of the store and its former sales system, with its counter, bulk products, service and credit and delivery system. In other words, we are in the presence of tools aimed at improving rather than transforming the existing grocery business; they were machines designed to extend and preserve the grocer's gestures, not to remove them (admittedly, productivity gains always have the reduction of the workforce as their horizon, but at least the operation did not seek to change or abolish the occupations at stake). See, for instance, the almost complete collection in the catalogue of equipment supplier Dayton, a subsidiary of IBM, with its scales, coffee grinders, slicing machines, meat choppers, etc. (Fig. 1)

At first glance, one may consider the improvements I have just presented as irrelevant to food studies, since they intervene "around" food, but neither produce nor modify them, nor affect consumer behaviour. In this respect, they should even be removed from this article! However, this way of thinking implies that by strengthening service, store equipment preserved the grocer-consumer relationship, hence the local, word-of-mouth form of product qualification that dominated markets until the late nineteenth century. Moreover, by speeding up and modernising the handling of goods, they supported food distribution at the expense of home self-production. In this sense, they also played a transitory role, half way between the former economy of local markets and the move towards pre-sliced, pre-packaged goods that contributed to

\section{DAYTON - A complete line of Store Equipment - DAYTON}

Manufactured by a Company that has specialized for thirty-four years

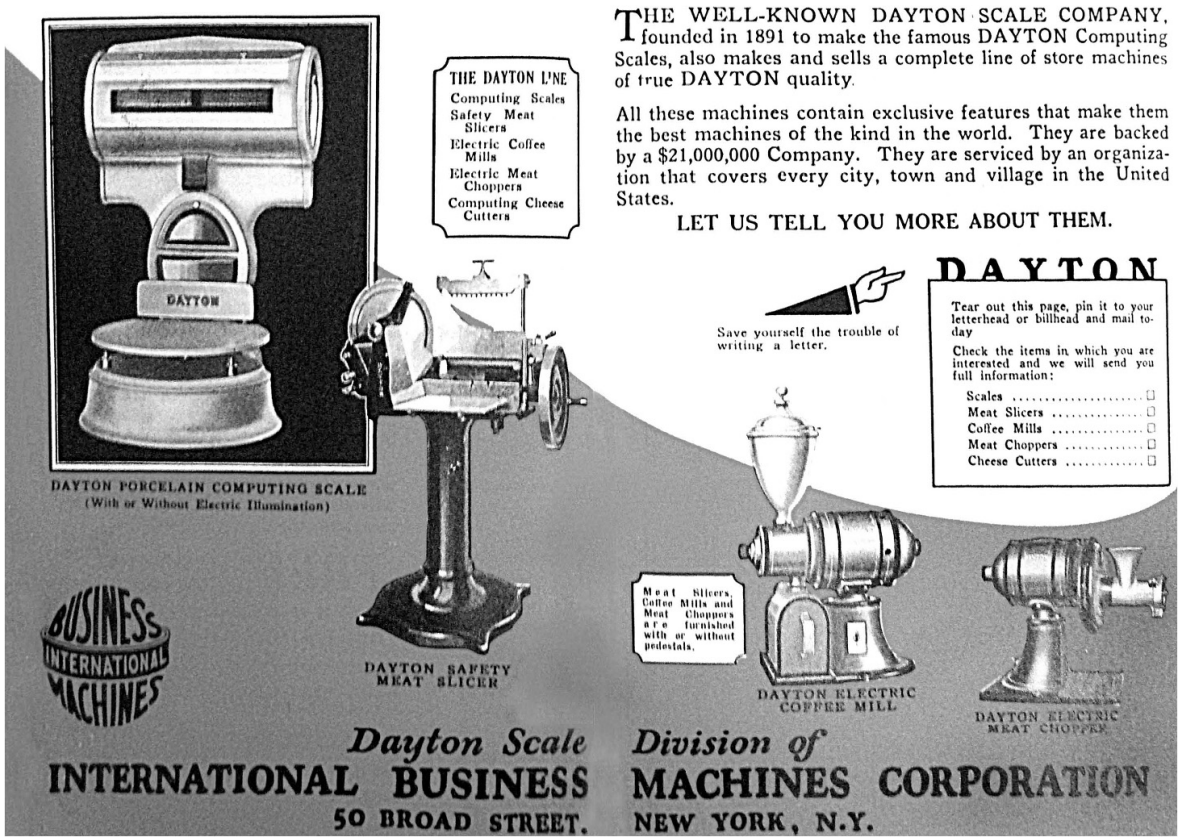

Fig. 1 "Dayton-a complete line of Store Equipment" (1925, 11, 40-41) 
unifying the American mass market (Tedlow 1990). This latter move was strongly encouraged and refined by other improvements such as telephone-assisted sales and motorised deliveries.

\section{From counter sales to telephone sales}

The telephone was first promoted as an instrument for supply-side actors and more specifically as a tool for active sales promotion. The use of the telephone as a market prospection instrument was the subject of many and precise testimonies. For example, every day, one store called at least ten people who had not yet bought anything from it (1923, 09, 94); another deliberately chose to "go after business in a most aggressive way", "instead of waiting for customers to come into [the] store as many retail establishments do" (1926, 10, 22). The promotion of the telephone thus consisted not only in highlighting its selling power but also, paradoxically, in presenting it as an instrument for cost reduction. Indeed, "the service grocer offers the housewife the saving effected through reduced store expenses, for, in the long run, less overhead is required to fill the telephone order than any other type of order" $(1926,01,34)$. Two reasons were cited for the telephone's positive contribution in terms of cost reduction. One reason was that service-oriented stores generally required less expensive locations than cash and carry stores and thus allowed very substantial savings on commercial leases. A second reason lay in the telephone's capacity to provide more rational business management through better sales organisation during the day $(1925,05,9)$.

In addition to presenting these benefits, the magazine described the organisational arrangements required for effective telephone sales, in terms of both division of labour and customer management. It provided additional guidance and examples of how to make the most of this selling method. It is quite remarkable to note that, since the 1920 s, some grocery stores had already been operating in a manner that amazingly foreshadowed the "call centres" that most contemporary specialists of telephoneassisted sales usually present as an exclusive innovation from the very end of the twentieth century (Fig. 2). In the grocery store of the Progressive Era, the division of labour between physical sales and telephone sales emerged very gradually: Progressive Grocer invited its readers to assign one employee to telephone selling $(1926,02,36)$; one case illustrates this practice in a store where a clerk was actually responsible for calling customers between 9 a.m. and 3 p.m. (1925, 09, 26). Although limited, the division of labour could nevertheless take a more sophisticated and developed form, as in the case of the Burns \& Lutz Company that organised two separate stocks, one for the store and the other for orders placed by telephone and delivered directly to customers, in order to avoid interferences between the two types of business (1923, $04,18)$. Last but not least, there existed several stores that introduced special services with employees exclusively assigned to telephone sales.

Admittedly, examples of telephone-assisted sales were most often found in large companies, mid-way between groceries and department stores. But these companies, however rare and special they may have been, followed a route others could take: see the Burns \& Lutz Company founded by two clerks who started from scratch. In presenting the telephone as a factor of their success, Progressive Grocer portrayed these companies as examples to be followed by all other grocers; it tried to inspire the 


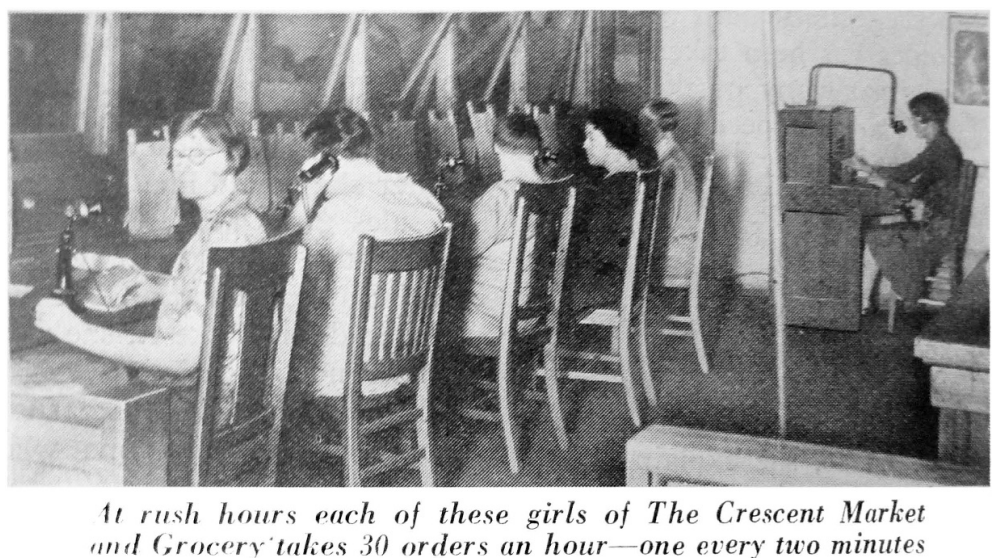

Fig. 2 Telephone sales department, Crescent Market and Grocery $(1927,11,27)$

hope that adopting distance selling could be the way to succeed, or at least to follow their tracks, and whatever the case, it would provide an opportunity for progress.

Although perhaps not immediately obvious, telephone-assisted sales had another major impact on food culture and practices. The effect of this technique is highly ironic: initially, telephone-assisted sales were presented as a way to preserve service by modernising it. However, the telephone was also a way to cite goods from a distance. Using the telephone for shopping - and thus depriving consumers of all their senses except hearing - increased uncertainties about the quality of the products and the risk of receiving deceptive deliveries. The best way to avoid this risk was to abandon the reference to generic goods and replace it with a precise request for a given brand name. In other words, telephone-assisted sales worked heavily in favour of standardised and branded products. Significantly, brands were not unaware of this dimension and, on the contrary, energetically seized the opportunity by encouraging telephone-assisted sales as a way to promote their distinctive advantages (Fig. 3).

\section{Motorised delivery service as the ultimate modernisation}

The telephone, however, was only the "penultimate" modernisation of service, because the final modernisation was yet to come (in my view at least), although, in fact, it developed simultaneously. Each telephone order is necessarily followed by a delivery: both operations are virtually inseparable, as an advertisement for Ford delivery trucks illustrates so well (see Fig. 4). Citing statistics from the Springfield Tea Co, this advertisement proudly proclaims "Salesmen with Ford Trucks carry Average 125 Calls and Deliveries Per day" $(1924,09,41)$. It would be wrong to interpret the motorisation of service as the dehumanised technicisation of transport, since the new vehicles, albeit stripped of their animal traction, were nevertheless inseparable from their drivers and thus from service - the behaviour of these drivers was also subject to optimisation efforts through training in courtesy and efficiency, as illustrated by a store named Weber $(1922,08,9)$.

The limitations of this type of modernisation were, of course, those imposed by competition and cost pressures. The question had already arisen with the telephone and 


\section{RINSO SALES TALKIES}
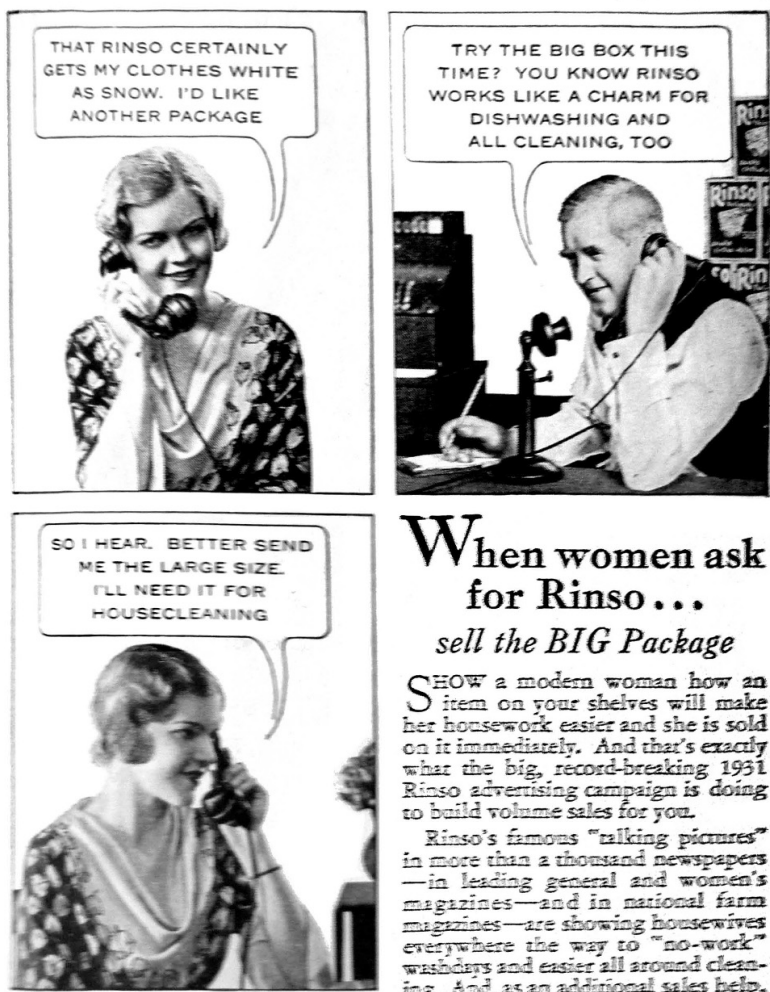

When women ask for Rinso... sell the BIG Package

Sirow a modem moman how an $\checkmark$ item on jous shelres will make her bousewotk easier and she is sold on it immediatel 7 . And that"s exactly what the big, record-breaking 1931 Wimso auterising campaign is doing to baild rolume sales for you.

Rinso's Exons "talking pictures" in Eore than a thomsand newspapers -in leading general and women's Ingtzines-and in mational farm migarines-are showing bousewites exerdwhere the way to "no-twouk" Tris in a Ad, as an addinional seles belp. Rin. And, as an addinomal sales belp; cart $t 0$ - 1 ilions aा ice a treek.

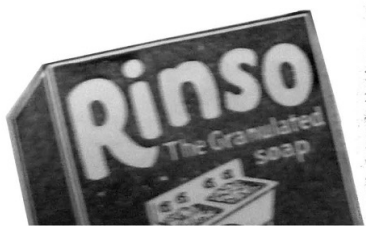

Wht not go afrer the Rinso reles thet are due jom. Displet Rimso ap fronc Feanue it in gour oxusdrertising Remiod jour oustomess that it does the best wuthiog and clexning

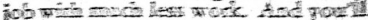
donble pour big parage taies in almos 10 a

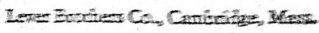

Fig. 3 When women ask for Rinso... (1931, 05, 13)

the problem was even greater with motorised delivery, which involves far higher expenses and investment than telephone service. However, and paradoxically, we learn that in the case of the Weber store, "The time and cost of delivery [was] cut down". Other contributions supported this type of statement with several arguments. One was to observe that the alleged savings from carried away sales were exaggerated. An article claimed that delivery was not an "extravagance" and noted that if the average basket purchased in a cash and carry store amounted to 81 cents, the average amount of an order placed by telephone and delivered to the customer amounted to $\$ 1.91$. Managing large orders was now less costly: an average of $4 \mathrm{~min}$ and $26 \mathrm{~s}$ was spent to sell a cash and carry order against $1 \mathrm{~min}$ and $57 \mathrm{~s}$ for a telephone order. The article also pointed out that the cash and carry system was an economic solution invented by the federal government to alleviate the difficulties of the war, the economic advantages of which had been greatly exaggerated, so that returning to deliveries ought to be defended 


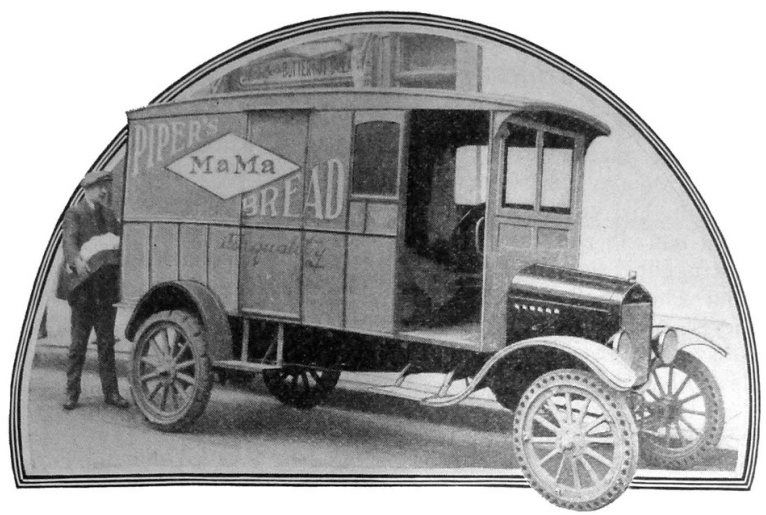

\section{How Fords Cut Food Delívery Costs}

One of the most convincing examples of cost-cutting in food delivery by the use of Ford Trucks in the experience of the H. Piper Company, wholesale bakers, Chicago.

Beginning ten years ${ }^{\top}$ ago with one Ford Truck the Piper Company built up a fleet of 40 One-Ton Trucks, each of which today is delivering baked goods to an average of one hundred stores and restaurants daily.

An average truck of this fleet is operated 306 days a year, traveling 10,700 miles, making 30,600 stops and carrying $2291 / 2$ tons, at an operating cost of just a trifle over 9 cents a mile, including maintenance and repairs, depreciation, tires, oil, gas, fixed expense, garage and insurance.

The fact that the Piper Company has re-ordered Ford Trucks year after year, and continues to reorder, is the most practical proof possible as to their satisfactory performance.

See Authorized Ford Dealers for further facts about this and other examples of Ford operation.

\section{To Fordize is to Economize}

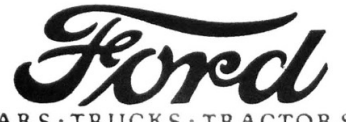

CARS - TRUCKS - TRACTORS

Fig. 4 How Fords Cut Food Delivery Costs $(1924,02,45)$

$(1925,05,9)$. A second argument was that, as with the telephone, the intensification/ modernisation of delivery could be presented not as an increased cost, but instead as a way to reduce costs through productivity gains obtained by mechanisation ("one dependable man and an inexpensive motor truck can economically replace the boys you use now", 1922, 05, 7), or due to the positive externalities associated with the use of trucks such as free savings or other advantages: having a truck made it easier to get fresh supplies; it enabled discounts to be negotiated with wholesalers using the argument that they would not have to deliver the goods; moreover, it offered a mobile advertising media that could promote the store throughout the city without incurring any additional expense (this argument was repeated several times in the magazine [1922, 05, 08; 1924 10, 15; 1925, 02, 18; etc.]). Lastly, a third argument consisted in relativising the cost of motorisation by noting that fewer than one grocer in 100 had an 
idea of the real cost of delivery and by developing, from this observation, scientific calculations that showed that the cost "per delivery" was actually very modest. Assuming that the price of a truck ranged from between 800 and 1500 dollars, and that its lifetime was estimated at 3 years for about 35 miles per working day, i.e. 35,000 miles over 3 years, an article estimated the monthly cost-including depreciation, taxes, maintenance and insurance, not to mention the driver's salary (US\$104) at $\$ 248$, or 27.5 cents per mile for 50 stops a day. The article concluded that the delivery price was 19 cents. Advertisers developed similar arguments, in particular the Ford Company, who, not content with the slogan "To Fordize is to Economize", took care to explain "How Fords Cut Food Delivery Costs" with many of calculations similar to the previous one, but giving the far lower result of 9 cents a mile.

With the motorisation of delivery, the technicisation of service underway inside the shop was extended outside, with similar consequences for shopping habits and food systems: it promoted widespread distribution by displaying the names of retailers painted on their trucks in the public space; moreover, it also promoted larger sales and goods related to storage and preserving such as the tinned foods I will now focus on. Not only did tinned goods change food patterns, but they contributed to the gradual replacement of service by self-service, thus inducing the very same changes.

\section{Replacement}

As we can see, the first modernisation aimed to improve the existing business rather than change it; it strove to keep grocers small yet efficient rather than replacing them by other devices and organisation schemes, even if in the process we see that it caused them to grow bigger. Incidentally, this modernisation surreptitiously promoted new kind of foods such as pre-packaged goods produced out of the home, and new relationships to them in terms of product qualification, size of purchases, etc. These trends were soon dramatically extended by the second modernisation that took the form of the "replacement" of service by self-service solutions. This latter movement was, by contrast, purely transformative. Replacement is an interesting word: it means both (1) introducing an alternative model that takes the place of the previous one and (2) putting the existing elements in different places, so that a new pattern emerges from their new arrangement and combination. As we will see, packaged and tinned goods played a prominent role in this replacement scheme.

\section{From tasting to testing...}

Before the rise of modern mass markets, products were mostly sold in bulk. This kind of product display carried various risks, and packaging innovation emerged as a response to these risks. With bulk sales, it was possible to market very different things under the same generic name, thus opening up opportunities for fraud: with bulk sales, greedy producers could sell bad quality products at the price of good ones and thus make considerable profits. This fraud problem alarmed some producers who reckoned they were harmed by the unfair competition of lower quality products that were indiscernible to the individual consumer's eye. In order to highlight the difference, some producers packaged their products and put their brand name on it (Strasser 1989); 
others took court action that led to pure food and competition legislation. These two types of action finally forced the content and origin to be marked and, incidentally, the branded and packaged presentation of products. With bulk sale, only one choice was possible for the same generic product and the only way of assessing it was to taste, look at, touch and smell it. However, this shift was not solely due to the packaging innovation because packaging also had to find its place in a retail environment that had very good reasons to remain attached to bulk foods: with bulk food, the retailer had control of product origin, price and qualification; he could easily substitute one provider with another without the possibility of his customers noticing the substitution

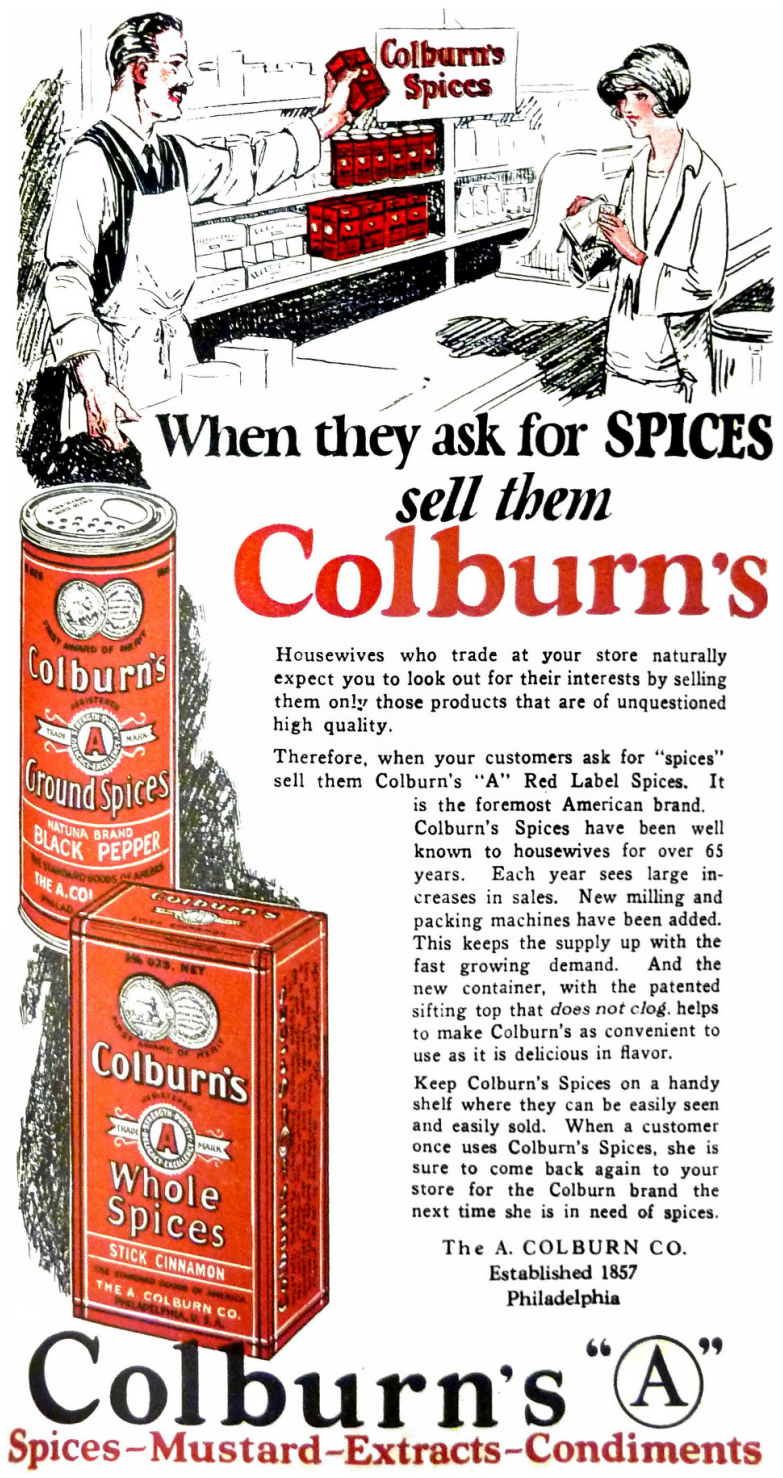

Fig. 5 When they ask for spices sell them Colburn's $(1923,06,61)$ 
(Strasser 1989). In other words, moving from bulk to packaged goods meant reorganising the grocery business itself. How did the packaging industry win over the grocer as a gate-keeper, or rather counter-keeper, and transform groceries? Let us examine an advertisement that provides the required clues (Fig. 5).

In this advertisement, the choice is no longer between sugar or spices as it was in the previous traditional general store economy, but between bulk spices vs. packaged spices, or perhaps already between Brand X spices and Colburn's spices. The oldest and simplest way to interact with objects is a hand-to-hand type of relationship. It is what the French sociologist Laurent Thévenot calls the "regime of familiarity" (Thévenot 2001) in which the choice of the object cannot be distinguished from its consumption. In the old regime, as it were, choosing meant consuming. Choosing meant engaging oneself in an immediate, direct and physical experience. Hesitation, far from hindering the consumer from grasping an object, instead hastened its taking through a direct and "polysensorial" evaluation of what was taken. I propose calling this direct, immediate and physical evaluation of products "tasting". In tasting, the process of choosing and the consumption experience are indiscernible and entirely linked to the senses.

With packaged goods however, it became possible not only to hesitate between two examples of the same product, but the same product could also receive two different presentations. With packaging, differences could be highlighted or invented. Moreover, tasting, touching or smelling the products became impossible, and the consumer was thus forced to refer to an indirect and scriptural evaluation of the goods. The introduction of packaging prevents any direct access to the object; it multiplies the possible definitions; it forces the consumer to choose before consuming (Mallard 2007); it thus builds a clear barrier between choice and consumption. This separation between choice and consumption led to specialisation. Since the consumer was no longer able to evaluate products that were increasingly packaged, complex or opaque, she delegated a growing part of her choice procedure to the objects themselves, or rather to their "managers". Consumers relied on information provided by producers, consumer guides, labels and certificates, and judgment networks (Karpik 2010). I propose calling this indirect, sequential and abstract mode of product evaluation "testing". With testing, the choice procedure and the consumption experience are distinct and specialised. While tasting relies on an experience that is individual, subjective, polysensorial and global, testing engages experiences that are instead experimental; these experiments are collective, abstract, objective and analytical all at the same time.

The outcome of packaging and testing was the addition of a whole series of dimensions to the product. However, rather than highlighting the product itself, these dimensions instead diverted attention from it. In order to differentiate their products, producers took advantage of the scriptural space of packaging to bestow the product with new properties: trademarks, symbols, consumer services, certificates and other third-party guaranties. In order to remain in the race, competitors adopted these successive and successful innovations. They also proposed new ones in an endless game of mimicry and differentiation. In the process, the consumer learnt new ways of product evaluation that were more plural, distant and abstract. Taste became both broadened and redefined. Sensations blended into the wider sphere of consumer preferences praised in economics; consumers learnt to like some entities that were a priori inaccessible to the senses, such as vitamins, for example (Fig. 6). 


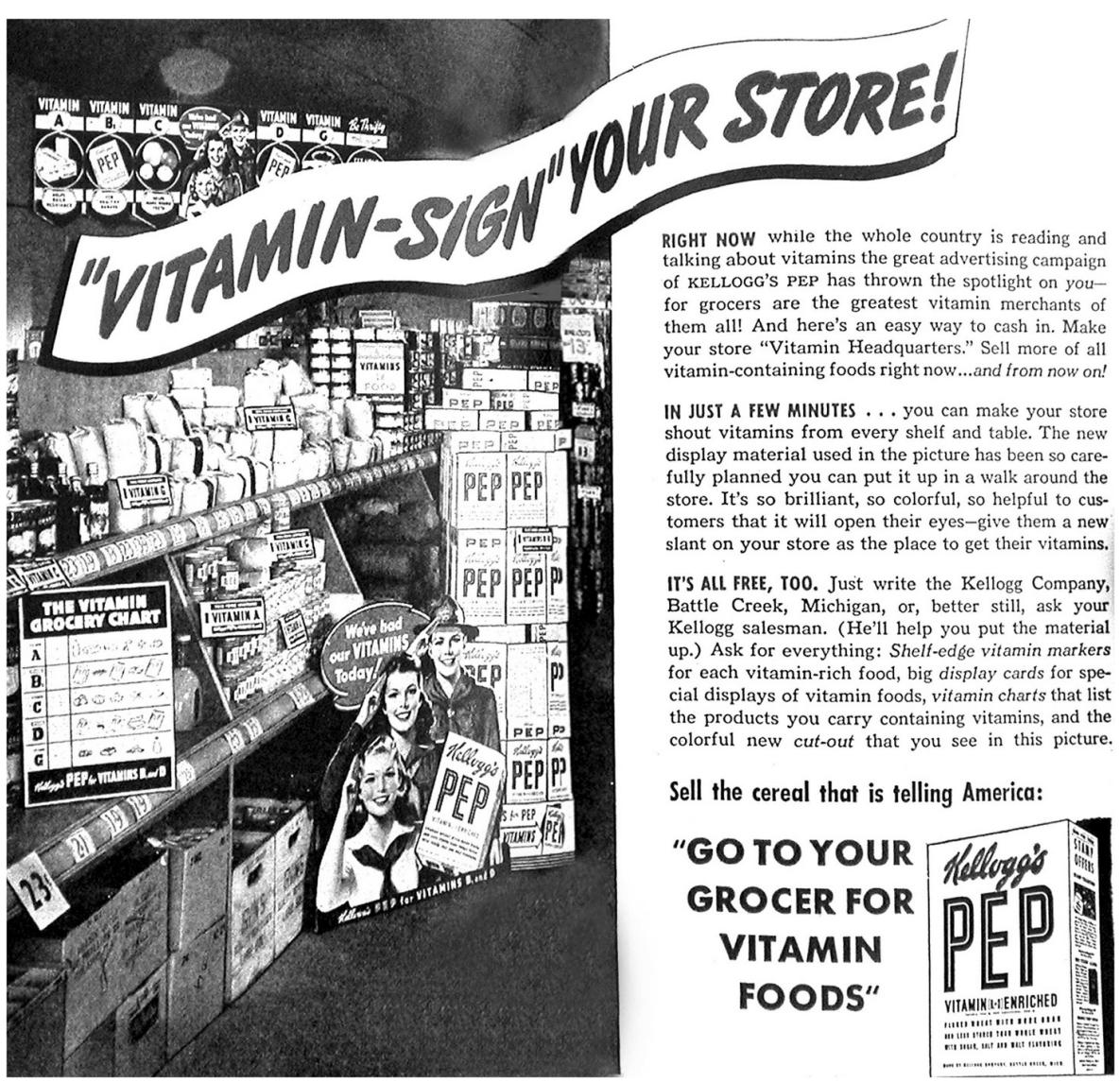

Fig. 6 Vitamin-sign your store! (1941, 03, 142-143)

Packaging and testing have two virtues. The first and most astonishing is that packaging enables us to taste what is tasteless, to see what is invisible, to smell what is odourless, to touch what is impalpable and even to listen to what is mute, hence the paradox that far from interrupting the dynamic of tastes as we may have thought, packaging instead increases and diversifies it through its very interruption. Packaging is a protective screen that hides things and hampers our senses, but it is also a projecting screen. As such, it shows us new elements and helps us experience sensations that our senses are unable to provide. ${ }^{2}$

Of course, the testing scheme tries to anticipate the tasting one by mobilising choice criteria, but these criteria are formalised and standardised. The choice is no longer personal; it is now a delegated procedure. The informed consumer chooses and tastes as a consumerist and even sometimes as a chemist who understands the meaning of complicated and abstract words such as "vitamins" (see above), "carbohydrates",

\footnotetext{
${ }^{2}$ I have just mentioned vitamins, which are socially valued, but I could also mention about nicotine, which is indicated so that the consumer passes on her way (Cochoy 2014b). This latter example shows that what is at stake when presenting products is not only taste but also disgust and that disgust is a way to challenge taste, for example when comparing the arguments of testing with the seductions of tasting.
} 
"fats", "cholesterol", and "GMOs". Her choice and consumption are now instrumented. They are embedded in an entire series of typical tools, frames, lists, criteria and behaviours that eventually release the consumer from a personal, physical and instant evaluation experience. In other words, the shift from tasting to testing illustrates a displacement of the evaluation mode, which moves from a physical perception to an intellectual judgment. It would appear that the development of the packaging economy led to the intellectualisation of consumption. All the dimensions that packaging adds to products have something in common: their analytical, symbolic and scriptural character. This abstract and rational character favours meanings rather than sensations, with perhaps the exception of visual impressions.

\section{How tins changed grocers, self-service foods and consumers}

The shift from tasting to testing arose from the technological innovations we are looking at and, in particular, innovation in product packaging and canning. As we will see, the propensity of tins to be examined, piled up and handled without affecting their content helped the goods move beyond the limit of the counter, escape retailers' mediation and be handled directly by consumers. Well before the advent of supermarkets, tins thus favoured the shift from service to self-service arrangements, the rise of modern consumerism and the development of the brand economy (Cochoy 2014a). Nevertheless, they had to convince grocers to promote them, and this was no easy task.

Tins had two major advantages. Firstly, this type of packaging, stackable and durable, required less furniture and less expensive display and storage fixtures than other products. Secondly and more importantly, because customers could handle the tins themselves without the risk of damaging them, and because tins could be clearly labelled with their contents, brand name and origin, tinned goods could "sell themselves" and reduce the need for service. However, and surprisingly enough, it seems that Progressive Grocer's journalists were not aware of these benefits or more likely that they were anxious not to disrupt the grocery industry's visceral attachment to customer service and product substitution, as well as its hostility towards brand names that curbed its role and freedom. Regardless of the reasoning, during the 1920s, Progressive Grocer avoided the most distinctive marketing appeals of the product they wanted to promote.

However, tin manufacturers and canners did "push" these benefits, but with extreme caution. In the Blue Ribbon Malt Extract advertisement (Fig. 7), most of the tins appear only behind the counter in the old-fashioned way, according to the traditional routine of grocer-mediated sales. The advertiser who designed this advertisement was well aware that most businesses were still operating their store on an "over-the-counter" basis, so it was prudent not to stay too far from common practice, working the angle "all other grocery things being equal", so to speak. However, in the same advertisement, it is clear that tins' capacity for being stacked without the need for shelves is highlighted, and their labels, which advertise their content, "speak" at the same time as-and soon instead of - the grocer. Thus, by virtue of their superior "display" capacity, tins slipped surreptitiously and silently from the background shelves to the talkative foreground of the counter, thus gradually replacing the grocer-still required since the counter had not disappeared, but already vanishing "behind" the "self-selling" goods. 

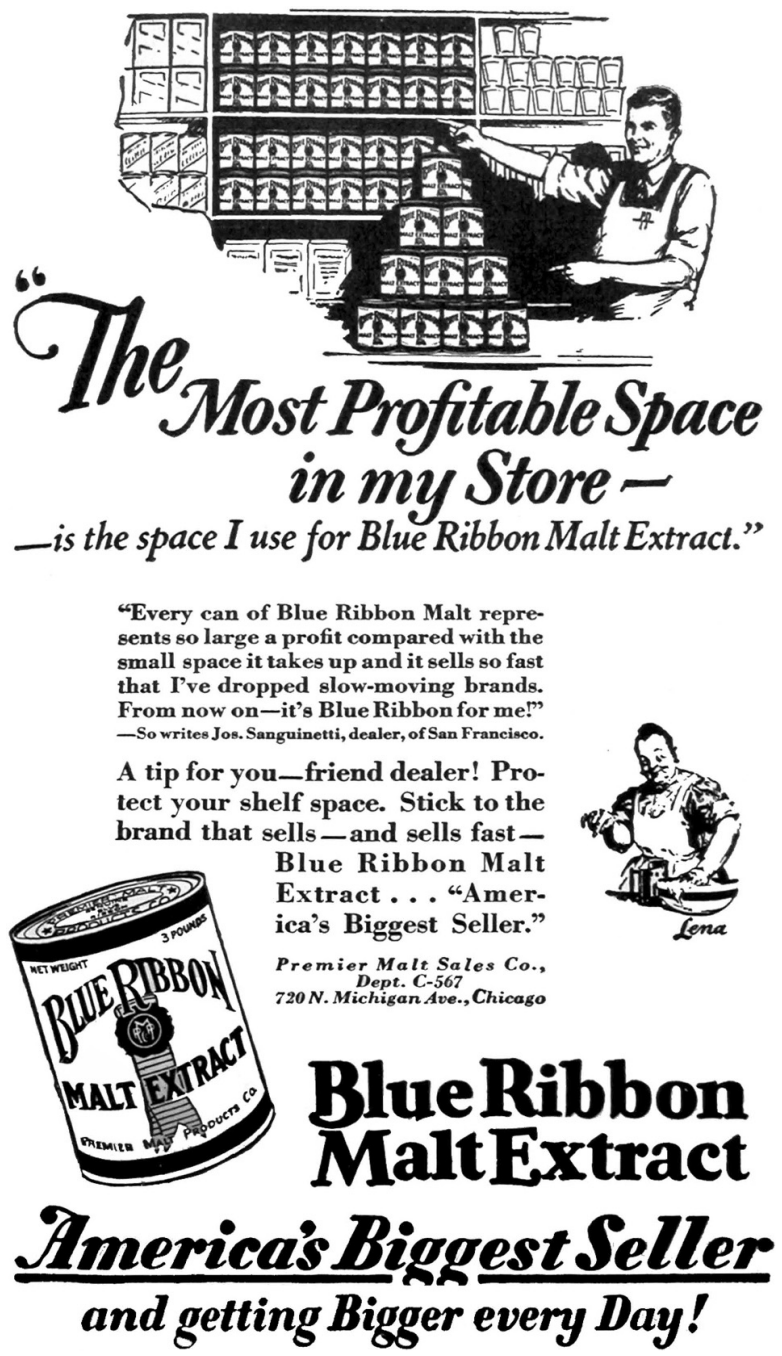

Fig. 7 Blue Ribbon Malt Extract (1929, 08, 51)

In the advertisement in Fig. 8, Libby's takes a step further. The staging is the same, with the double exposure of tin cans on shelves or in a stack and the presence of the grocer. However, the counter, now redundant, has disappeared, leading to new and subtle changes: by moving to the floor, the pile of tins has grown; in jumping to the other side of the counter, the stacked or shelved tins have become fully accessible to customers. Thus, as we gradually discover, tins initiated the self-service era in small and traditional grocery stores in the 1920s rather than in the larger, subsequent supermarkets. Of course, the transition was conservative: the grocer was retained, but his stacking was clearly reversible, able to become a taking gesture and transferable to the client; the purpose was to teach grocers "gently" that tins were not only stackable, as highlighted by the previous advertisements, but that they could also be left to be handled directly by clients without fear of material damage (being solid) or sanitary 


\title{
"Our sales show a 25\% increase yearly for 8 years with this plan"
}

\author{
writes L. DeVos, \\ of Seattle, Wash.
}

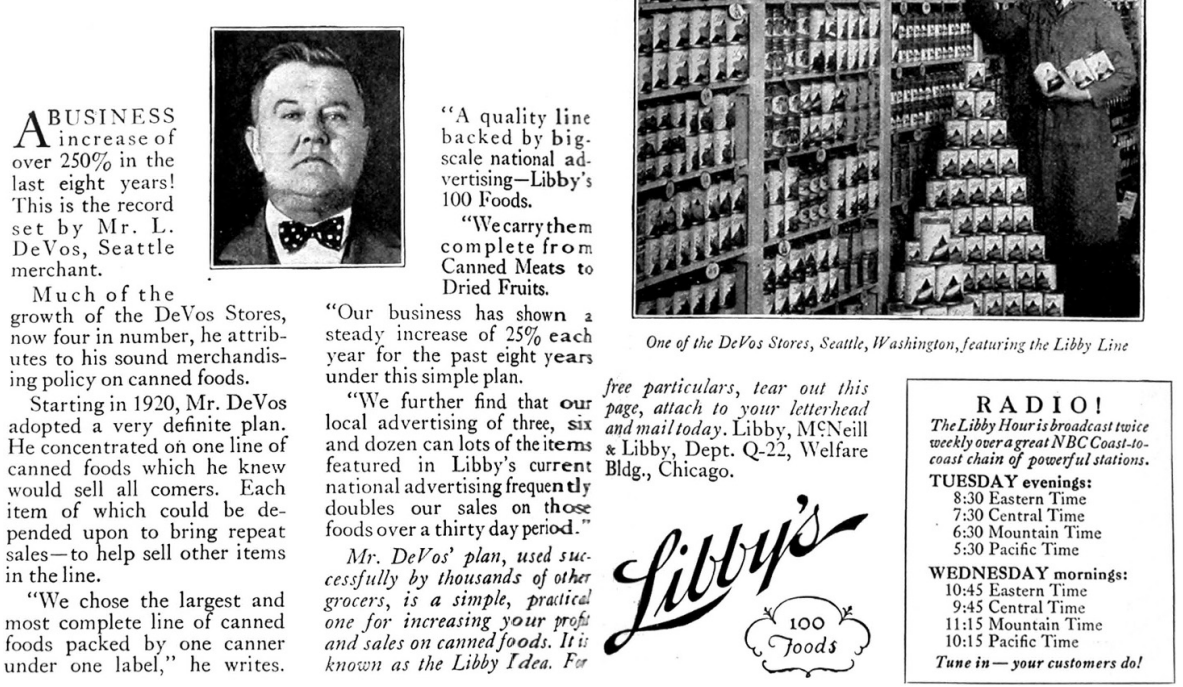

Fig. 8 Libby's plan (November 1929: 6-7)

problems (being hermetic). In other words, tin cans contributed to enlarging the setting of the grocer's store: they extended and rearranged its furniture so that, in the end, the grocery store could expand and later become a giant. Tins clearly encouraged the grocery store's shift towards self-service, the curtailing of service grocers and the rise of giant retailers and mass consumption, and more importantly, all the tremendous changes in food cultures that are the distinctive features of modern markets: labelled and branded products, externally qualified and controlled goods, industrial and standardised foods and so on, not to mention the new consumers' identities that go with them: bargain hunters, brand addicts, health-conscious consumers, consumerist activists, organic shoppers and all the other kinds of consumers that marketing, consumer research and the sociology of consumption and other food studies now endlessly explore and describe.

\section{Conclusion}

With the description of the dual movement of service's betterment followed by its replacement, we can see the importance of the material infrastructure and distribution techniques at work in food cultures and food practices. On the one hand, these "market agencements" (Callon 2016) or "market-things" (Cochoy 2007) are heavily loaded with particular goals, but on the other hand, these goals are local and unconnected, restricted 
to the distinct projects of their manufacturers and promoters. Moreover, these devices also demonstrate some unexpected properties that play a role, such as the robustness and opaqueness of tin cans and their propensity to favour mass display, product labelling and so on. These two characteristics were combined to reshape the general characteristics of the market scene, to the point that they ended up creating a new economy. This economy is still about food, but now food has been significantly redefined by its containers: the box, the words and the shops. With the progressive hinging of the new devices and techniques, there was a shift from self-production of fresh or dry products to the new, industrialised foods, where eaters eat not just foods but also symbols, brands and chemicals. Thanks to the new technologies and the rise of the self-service system, consumers adopted new rhythms: they began to buy, stock and circulate more, distorting time and space according to their new moves and moods. New social relationships emerged: consumers were freed from their dependency on the grocer and experienced the ambiguous freedom of the self-service shopper. The selfservice consumer was now able to "shop alone", without being subjected to product substitution or the often humiliating remarks of the grocer (Du Gay 2004). However, the same consumer was also exposed to a huge web of market-things that led to her shopping and eating differently; these market-things succeeded to do so all the more effectively because the consumer believed herself to be free and hence lowered her guard. In contemporary food markets, free consumers are subjected to the tyranny of choice, to quality and price dilemmas; the former obvious and heavy social control exerted by grocers has been replaced by a softer and more discreet delegated technological environment where interaction with machines helps reshape private identities according to patterns that are extremely well identified by Natasha Schüll (2012) in her book, Addiction by Design. All in all, there is a lesson to be learnt from this: we should not restrict the study of consumption to the study of consumers; we should not limit the study of foods to food culture or food practices. The study of eaters' cultures and practices matters, of course, but understanding the latter may certainly be enriched by taking into consideration what occurs beyond and around them. We have learned a great deal from food studies, but we may learn even more by extending the view further, by focusing on all the little market-things that ceaselessly reshape consumer behaviour (Cochoy 2010).

Open Access This article is distributed under the terms of the Creative Commons Attribution 4.0 International License (http://creativecommons.org/licenses/by/4.0/), which permits unrestricted use, distribution, and reproduction in any medium, provided you give appropriate credit to the original author(s) and the source, provide a link to the Creative Commons license, and indicate if changes were made.

\section{References}

Araujo, L., Finch, J. \& Kjellberg, H. (2011). Introduction to e-special on market studies. Marketing Theory, 1470-5931, available online at: http://mtq.sagepub.com/site/virtual_special_issues/virtual_issue_market_ studies_introduction.pdf.

Bowlby, R. (2001). Carried away: the invention of modern shopping. New York: Columbia University Press. Buenker, J. D., \& Kantowicz, E. R. (Eds.) (1988). Historical dictionary of the Progressive Era, 1890-1920. New York: Greenwood Press. 
Callon, M. (1986). Some elements for a sociology of translation: domestication of the scallops and the fishermen of St-Brieuc Bay. In J. Law (Ed.), Power, action and belief: a new sociology of knowledge? (pp. 196-223). London: Sociological Review Monograph, Routledge and Kegan Paul.

Callon, M. (1998). An essay on framing and overflowing: economic externalities revisited by sociology. In M. Callon (Ed.), The laws of the markets (pp. 244-269), Sociological Review Monographs Series. Oxford: Blackwell.

Callon, M. (2016). Revisiting marketization: from interface-markets to market-agencements. Consumption Markets \& Culture, 19(1), 17-37.

Callon, M., Millo, Y., \& Muniesa, F. (Eds.). (2007). Market devices, Sociological Review Monographs. Oxford: Blackwell.

Cochoy, F. (2007). A sociology of market-things. On tending the garden of choices in mass retailing. In M. Callon, F. Muniesa, \& Y. Millo (Eds.), Market devices (pp. 109-129), Sociological Review Monographs, 55(777). London: Blackwell.

Cochoy, F. (2009). Driving a shopping cart from STS to business, and the other way round. On the introduction of shopping carts in American grocery stores (1936-1959). Organization, 16(1), 31-55.

Cochoy, F. (2010). Reconnecting marketing to "market-things": how grocery equipments drove modern consumption. In L. Araujo, J. Finch, \& H. Kjellberg (Eds.), Reconnecting marketing to markets: practice-based approaches (pp. 29-49). Oxford: Oxford University Press.

Cochoy, F. (2014a). "Trojan cans". How did the self-service economy emerge? Limn, 4, 16-19, available online at: http://limn.it/trojan-cans/.

Cochoy, F. (2014b). Cigarettes packages: the big red chevron and the 282 little kids. In N. Thrift, A. Tickell, \& S. Woolgar (Eds.), Globalisation in practice (pp. 165-170). Oxford: Oxford University Press.

Cochoy, F. (2016). On the origins of self-service. London and New York: Routledge.

Cochoy, F., \& Dubuisson-Quellier, S. (2013). The sociology of market work. Economic Sociology, the European Electronic Newsletter, 15(1), 4-11 http://econsoc.mpifg.de/archive/econ_soc_15-1_docm. pdf\#page $=4$.

Cochoy, F., Trompette, P., \& Araujo, L. (2016). From market agencements to market agencing: an introduction. Consumption, Markets and Culture, 19(1), 3-16.

Counihan, C. (2004). Around the Tuscan table: food, family and gender in twentieth century Florence. London: Routledge.

Deutsch, T.A. (2001). Making change at the grocery store: government, grocers, and the problem of women's autonomy in the creation of Chicago's supermarkets, 1920-1950. PhD dissertation, University of Wisconsin-Madison.

Du Gay, P. (2004). Self-service: retail, shopping and personhood. Consumption, Markets \& Culture, 7(2), 149-163.

Fischler, C. (1990). L'Homnivore. Le goût, la cuisine et le corps. Paris: Odile Jacob.

Grandclément, C. (2008). Vendre sans vendeurs: sociologie des dispositifs d'achalandage en supermarché, thèse pour le doctorat en socio-économie de l'innovation. Paris: École Nationale Supérieure des Mines de Paris.

Hennion, A. (2015). The passion for music: a sociology of mediation. London: Ashgate.

Karpik, L. (2010). Valuing the unique: the economics of singularities. Princeton: Princeton University Press.

Latour, B. [Johnson J.] (1988). Mixing humans with non-humans: sociology of a door-closer. Social Problems, 35(3), 298-310.

Latour, B. (1999). Factures/fractures. From the concept of network to that of attachment. Res, 36(Autumn), 20-31.

Lave, J., Murtaugh, M., \& de la Rocha, O. (1984). The dialectic of arithmetic in grocery shopping. In B. Rogoff \& J. Lave (Eds.), Everyday cognition. Its development in social context (pp. 67-94). Cambridge: Harvard University Press.

Levi-Strauss, C. (2006). The culinary triangle. In C. Counihan \& P. Van Esterik (Eds.), Food and culture: A reader. London and New York: Routledge.

Mallard, A. (2007). Performance testing: dissection of a consumerist experiment. In M. Callon, Y. Millo, \& F. Muniesa (Eds.), Market devices (pp. 152-172). Oxford: Blackwell.

McFall, L. (2009). Devices and desires: how useful is the "new" new economic sociology for understanding market attachment? Sociology Compass, 3(2), 267-282.

Norman, D. A. (1988). The psychology of everyday things. New York: Basic Books.

Parasecoli, F., \& Scholliers (Eds.). (2012). A cultural history of food (Vol. 6). Oxford: Berg Publishers.

Poulain, J.-P. (2002). Sociologies de l'alimentation, les mangeurs et l'espace social alimentaire. Paris: Presses Universitaires de France.

Poulain, J.-P. (2009). Sociologie de l’obésité. Paris: Presses Universitaires de France. 
Schüll, N. (2012). Addiction by design: machine gambling in Las Vegas. Princeton: Princeton University Press.

Spellman, S. V. (2016). Cornering the market, independent grocers and innovation in American small business. Oxford: Oxford University Press.

Strasser, S. (1989). Satisfaction guaranteed, the making of the American mass market. New York: Pantheon Books.

Tedlow, R. S. (1990). New and improved. The story of mass marketing in America. New York: Basic Books. Thévenot, L. (2001). Pragmatic regimes governing the engagement with the world. In K. Knorr-Cetina, T. Schatzki, \& E. v. Savigny (Eds.), The practice turn in contemporary theory (pp. 56-73). London: Routledge.

Wansink, B., \& Van Kleef, E. (2014). Dinner rituals that correlate with child and adult BMI. Obesity, 22(5), e91-e95.

Wilk, R. (Ed.). (2006). Fast food/slow food: the cultural economy of the global food system. Walnut Creek: Altamira Press. 